\title{
An Empirical Study on the Effectiveness of Technical Analysis in China's Stock Markets
}

\author{
Kai CHEN \\ School of Economics and Management \\ Nanjing University of Science and Technology \\ Nanjing, China \\ e-mail: 387673093@qq.com
}

\author{
Guangping HUI \\ School of Economics and Management \\ Nanjing University of Science and Technology \\ Nanjing, China \\ e-mail: huigp@e165.com
}

\begin{abstract}
The weak form of the EMH proclaims that it is not possible to sustain above normal returns over the long run. However, in recent years, scholars have found that technical analysis trading strategy can obtain significant excess returns in different markets. In this paper, we use the CSI 300 Index, Moving average trading strategy, KDJ strategy and MACD strategy to study the weak effective of China's stock market. Through empirical research, it is concluded that the some technical analysis can obtain significant excess returns in the short term, and the Chinese stock market has not yet reached the weak efficient market.
\end{abstract}

Keywords-technical analysis; market effectiveness; bootstrap nonparametric test

\section{INTRODUCTION}

In the stock market, in order to obtain excess returns, scholars and investors are keen to analyze the stock. The analytical methods mainly include technical analysis and fundamental analysis. Fundamental analysis, also known as value analysis, the intrinsic value of the enterprise as the main research object, analysis of macroeconomic situation, industry development prospects and business conditions, to calculate the intrinsic value of corporate stocks, and make the appropriate investment strategy. Compared with the value analysis method, the technical analysis lack of theoretical support, and ignore the company's financial situation and operating condition, the validity of the technical analysis has also been questioned by the scholars.

The first tenets of the EMH began with an empirical work by Kendall in 1953: «The Analysis of Economic Time Series», where he notices the randomness character of price movement. Later, John Muth (1961) introduced the concept of "rational expectations" in his paper «Rational Expectations and the Theory of Price Movements», one of the major pillars of the EMH. In 1965, Paul Samuelson pointed out that in an information-friendly market, if price changes fully reflect the expectations and ownership of all market participants, then the price change is unpredictable. Finally Eugene Fama compiled the theory as we know it today. In 1970, Fama summed up this hypothesis into a wellknown axiom, that is, under the condition that the structure of the various information sets was known to the market participants, "the price fully reflects all the available information". The effective market hypothesis includes three forms: the weak effective market hypothesis, the semi-strong effective market hypothesis and the strong market hypothesis; the weak effective market means that the current price fully reflects all the information contained in the historical price, the future price is determined by information contained outside the historical price, but not related to past historical prices. The weak form of the EMH proclaims that it is not possible to sustain above normal returns over the long run. This does not imply that one investor may achieve excess returns in a small period of time. However, in recent years, more and more scholars have found that technical analysis trading strategies can obtain significant excess profits in different markets. Different scholars use different research methods, different sample data, even if use the same data will come to different results.

This paper mainly uses the method of empirical research and comparative analysis, mainly based on empirical research, supplemented by comparative analysis. In the empirical study, the daily rate of return of the trading strategy based on these technical indicators was constructed based on the variable moving average (VMA), fixed moving average (FMA), KDJ, MACD to do empirical research. The problem of significance of excess returns, transaction costs and asynchronous trade issues are handled by nonparametric bootstrap methods, Break-Even Cost and lagging revenue. The purpose of this study is to re-verify the effectiveness of technical analysis in China. If the empirical results show that the technical analysis trading strategies can achieve significant excess returns, which means this technical analysis strategy is practical and effective, China's stock market did not meet the requirements of weak effective market. If the empirical results show that this technical trading strategy cannot produce significant excess returns, means this trading strategy does not work for a time period, it doesn't mean all TA strategies do not work ever, in any time period, in every Chinese stock market.

On the basis of previous studies, this paper has made innovations in the following aspects: the previous research on the effectiveness of technical analysis mainly focused on the moving average trading strategy, including variable moving average trading strategy (VMA), fixed moving average (FMA) and Breakthrough Trading Strategy (TRB). However, there is little research on the trading strategy of other indicators such as KDJ index and MACD index, so that there is a gap in the research of technical analysis. At the same time, this paper also improve previous moving average 
trading strategy - asynchronous transaction problem, we use "buy lag one day, sell no lag" approach.

\section{LITERATURE REVIEW}

In 1932, Charles Dow, founder of Charles Jones, wrote a series of articles in the Wall Street Journal marks the birth of technical analysis. Subsequently, Elliott mentioned wave theory, followed by Gann theory and other technical analysis methods came into being, enriched the technical analysis system. Technical analysis in the financial investment community with simple chart and easy to use has been a wide range of attention and application, but technical analysis has also been questioned, technical analysis lack of strong theoretical support.

Some scholars through empirical research concluded that technical analysis is invalid. Fama and Blume (1965) [1] select the daily closing price of 30 companies in the Dow Jones Industrial Average from 1956 to 1962 to examine multiple filter rules. When the transaction commission and transaction costs are not taken into account, only when $\mathrm{X}=$ $0.5 \%$, the filter rules produce a higher yield than the buy and holding strategy, even under some filter rules, the average yield of 30 companies is negative; at the same time, after considering the commission and transaction costs, the only excess yield also changed from $0.1152 \%$ to $-1.0359 \%$. Thus, Fama and Blume argue that changes in historical prices cannot predict future asset price movements. By 1970, Fama [2] summed up the random walk hypothesis and its empirical research, proposed an effective market hypothesis: if the stock price can quickly and fully reflect the information available on the market, then the market is effective. Neely, Weller and Dittmar [3] used genetic programming in 1997. By selecting the six different conversion rates from 1981 to 1995, it was found that technical analysis can achieve significant excess return in the sample, but if you consider the system risk, this excess rate of return will disappear; Nelly, Weller use high-frequency data, use the application of linear prediction model, after considering the actual transaction costs and trading hours, the technical analysis cannot obtained excess returns. Fyfe, Mareny, Tarbert [4] using the bootstrap significance test, select the sharp ratio as risk adjustment ratio, after the risk adjusted, the excess return from technical analysis gradually reduced.

However, some scholars through empirical research concluded that technical analysis is effective, technical analysis can bring excess returns. Efron (1979) [5] proposed using the bootstrap method instead of the traditional $t$ statistic test. The traditional $\mathrm{t}$ statistic requires that the yield of the hypothesis test should be subject to a normal distribution, but this is inconsistent with the fact that the stock's. However, until the empirical study of Brock, Lakonishok and LeBaron (1992) [6], the bootstrap method was used to test the significance of excess returns in trading strategies. In the empirical test, Brock et al. select the daily return of the Dow Jones Industrial Average from 1897 to 1986, using the moving average. The empirical results show that buy signal is significantly higher than the normal return. Thus, they argue that the invalidation of technical analysis is too hasty. Bessembinder and Chan [7], found that in Japan,
Hong Kong, China, Korea, Malaysia, Thailand and China Taiwan have the ability to predict the excess returns; and they find that the trading rules generated by the US market can also bring some excess returns to the Asian market at the same time. Dai jie and Wu Kang ping (2002) [8] use the moving average trading strategy to compare 17 market index earnings to do Empirical Research. It is found that the moving average trading strategy has some predictive power to some extent. SUN Bibo [9], intercepted the data of the Shanghai Composite Index from 1990 to 2003, use the moving average trading strategy and the trading strategy of the trading range for empirical test. It was found that some trading strategies can obtain significant excess returns. China's stock market has not yet reached to a weak market, because the empirical results of the test still use the traditional $t$ statistics, may be biased. SUN Bibo [10] used the same data, and the bootstrap method is used to re-test the forecasting ability of the moving average trading strategy. It is concluded that the short-term moving average line trading strategy can obtain excess returns and short- Ability.

In addition, some scholars have come to other conclusions: Sullivan, Timmermann, White [11], for the data snooping effect, proposed a white test method to remove the data snooping, the technical analysis can bring excess returns, technical analysis can obtained excess returns, but with the improvement of market effectiveness, the excess returns disappear slowly. Li Sha and Li Hong gang [12] found that the moving average trading strategy on China's Shanghai index is effective, but for stocks price forecast is invalid. In contrast to other countries' indicators, it is found that moving average trading strategies are not predictive in countries where capital markets are developed.

Although many empirical studies show that the technical analysis is effective in China's stock market, most of these empirical studies have some problems, making the test results difficult to convince, such as the early empirical study use $t$ statistic, ignore asynchronous transactions, transaction costs and so on. At the same time, most scholars are focused on the moving average trading strategy, the lack of attention to other technical indicators.

\section{THE TRADING STRATEGY}

In this paper, technical indicators are based on closing price and trading volumes. Common technical indicators include moving average (MA), MACD and KDJ. For the moving average strategy, we choose the same technical analysis indicators as Brock (et al., 1992) [6], Variable Moving Average (VMA) and Fixed Moving Average (FMA).

\section{A. Variable Moving Average Strategy (VMA)}

First, we should calculate a long and a short moving arithmetic average price:

$\mathrm{MA}_{\mathrm{ij}}=\frac{1}{\mathrm{i}} \sum_{\mathrm{j}-\mathrm{i}+1}^{\mathrm{j}} \mathrm{P}$

Where i represent $s, 1, s$ represent the number of short average days, 1 represent the number of long average days, $j$ represents the first few days, and $\mathrm{P}$ represents the closing 
price. In this paper, six sub-strategies $(1,5),(1,20),(1,60)$, $(5,20),(5,60),(20,60)$ were selected.

When the " $\mathrm{MA}_{\mathrm{sj}}$ " is bigger than the " $\mathrm{MA}_{\mathrm{lj}}$ ", the stock price is considered to be on the rising channel and we should buy stocks (1 represent buy stocks), When the "MA $\mathrm{sj}$ " is smaller than the "MA $\mathrm{Al}_{\mathrm{jj}}$ ", the stock price is considered to be on the declining channel and we should sell stocks (-1 represent sell stocks).

$$
\mathrm{Z}_{\mathrm{t}}= \begin{cases}1 & \mathrm{MA}_{\mathrm{s}} \geq(1+\mathrm{b}) \mathrm{MA}_{\mathrm{l}} \\ -1 & \mathrm{MA}_{\mathrm{s}} \leq(1+\mathrm{b}) \mathrm{MA}_{\mathrm{l}}\end{cases}
$$

Due to false signalling and high volatility may generate the "whipping effect". When the "short average" and "long average" values close to each other, which will generate " whipping effect "." whipping effect "will lead to a significant increase in the number of transactions and transaction costs, which will affecting the stability of the performance of the strategy. To solve this problem, we set a threshold $b$ to filter the signal. In this paper, $\mathrm{b}$ is equal to 0 (buy and sell), and $\mathrm{b}$ is equal to 0.01 (buy, sell and non).

\section{B. Fixed Moving Average Strategy (FMA)}

Compare FMA strategy and VMA strategy, the similar is that the two strategy should through comparing $\mathrm{MA}_{\mathrm{sj}}$ and $\mathrm{MA}_{\mathrm{lj}}$ to decide whether to buy stocks or sell stocks, the difference is: the VMA strategy is a "T+1" strategy, compare $\mathrm{MA}_{\mathrm{sj}}$ and $\mathrm{MA}_{\mathrm{lj}}$ every day ; while the FMA strategy is a " $\mathrm{T}+\mathrm{K}$ " strategy, where $\mathrm{K}$ represent the number of holding days, for example, in the first day, we compare $\mathrm{MA}_{\mathrm{sj}}$ and $\mathrm{MA}_{\mathrm{lj}}$ to decide whether to buy or sell, holding $\mathrm{K}$ days, during the $\mathrm{K}$ days, we don't need to compare $\mathrm{MA}_{\mathrm{si}}$ and $\mathrm{MA}_{\mathrm{lj}}$, in $\mathrm{K}+1$ days we should compare $\mathrm{MA}_{\mathrm{sj}}$ and $\mathrm{MA}_{\mathrm{jj}}$ to decide whether to buy or sell, and the next $\mathrm{K}$ days we don't need to compare $\mathrm{MA}_{\mathrm{sj}}$ and $\mathrm{MA}_{\mathrm{lj}}$ and so on. As with the VMA strategy, the FMA strategy also uses 1\% threshold to suppress the effect of the "whipping effect".

\section{MACD Strategy}

MACD is a double smooth moving average, the main three parameters: short-term length of time (commonly used 12 days), long-term length (commonly used 26 days) and closing price. Calculate the MACD value, first of all, we need to calculate the average length of the two mean (EMA):

$$
\begin{aligned}
& \operatorname{EMA}(12)_{\mathrm{t}}=\frac{11}{13} \times \operatorname{EMA}(12)_{\mathrm{t}-1}+\frac{2}{13} \times \mathrm{C}_{\mathrm{t}} \\
& \operatorname{EMA}(26)_{\mathrm{t}}=\frac{25}{27} \times \operatorname{EMA}(26)_{\mathrm{t}-1}+\frac{2}{27} \times \mathrm{C}_{\mathrm{t}}
\end{aligned}
$$

Calculate the (DIF), (DEA) and MACD value:

$$
\begin{aligned}
& \mathrm{DIF}_{\mathrm{t}}=\operatorname{EMA}(12)_{\mathrm{t}}-\operatorname{EMA}(26)_{\mathrm{t}} \\
& \mathrm{DEA}_{\mathrm{t}}=\frac{4}{5} \times \mathrm{DEA}_{\mathrm{t}-1}+\frac{1}{5} \mathrm{DIF}_{\mathrm{t}} \\
& \mathrm{MACD}_{\mathrm{t}}=2 \times\left(\mathrm{DIF}_{\mathrm{t}}-\mathrm{DEA}_{\mathrm{t}}\right)
\end{aligned}
$$

MACD trading strategy mainly reference MACD value. When the MACD value from negative to positive, we should buy stocks. When MACD value from positive to negative, we should sell stocks.

\section{KDJ Strategy}

Because the random indicators were $\mathrm{K}$ line, $\mathrm{D}$ line and $\mathrm{J}$ line composition, so often referred to in the country as KDJ indicators. The stochastic index focuses on the relationship between the final price and the fluctuation range over a period of time, which can reflect the real trend of the price. Its calculation method is also quite complex, first need to calculate $\mathrm{n}$ ( $\mathrm{n}$ in the investment practice generally equal to 9) day RSV, detailed calculation method is as follows:

$\operatorname{RSV}(\mathrm{n})_{t}=\frac{\mathrm{C}_{\mathrm{t}}-\mathrm{L}(\mathrm{n})_{\mathrm{t}}}{\mathrm{H}(\mathrm{n})_{\mathrm{t}}-\mathrm{L}(\mathrm{n})_{\mathrm{t}}} \times 100$

$\mathrm{K}(\mathrm{n})_{\mathrm{t}}=\frac{2}{3} \mathrm{~K}(\mathrm{n})_{\mathrm{t}-1}+\frac{1}{3} \mathrm{RSV}(\mathrm{n})_{\mathrm{t}}$

$\mathrm{D}(\mathrm{n})_{\mathrm{t}}=\frac{2}{3} \mathrm{D}(\mathrm{n})_{\mathrm{t}-1}+\frac{1}{3} \mathrm{~K}(\mathrm{n})_{\mathrm{t}}$

$J(n)_{t}=3 K(n)_{t}-2 D(n)_{t}$

Where $\mathrm{C}_{\mathrm{t}}$ represents the closing price of the stock at $\mathrm{t}$ day, $H(n)_{t}$ represents the highest price of the stock in the last $\mathrm{n}$ days, $\mathrm{L}(\mathrm{n})_{\mathrm{t}}$ represents the lowest price of the stock in the last $\mathrm{n}$ days. The initial value of $\mathrm{K}$ and $\mathrm{D}$ is 50 . The KDJ trading strategy is: when $\mathrm{K}$ line from the bottom up through the $\mathrm{D}$ line, buy stocks; when $\mathrm{K}$ line from the top down through the D line, sell stocks.

\section{MODEL IMPROVEMENT}

This section provides an improved methods to the significance test, data selection, transaction cost issues, and asynchronous transaction issues.

\section{A. Significance Test}

In the past, the significance test of the excess returns of the trading strategy is generally measured by $\mathrm{t}$ test method, the mean and variance in the data are calculated, then $t$ statistic is calculated and the significance is judged. However, the $t$ test requires that the data should be subject to a normal distribution, and the stock returns generally have sharp peaks and fat tail distributions, so if we use the traditional t test, will make the test results are biased, the test results are not reliable.

Efron $^{[5]}$ proposed the bootstrap method instead of the traditional $t$ statistic to test the significance of the excess return of the trading strategy. The bootstrap method does not require the distribution of the rate of return series, and can solve the problem of time-varying transaction strategy. In this paper, we use nonparametric bootstrap methods, the main steps are as follows:

Step 1: Assume that the H0: Technical trading strategy buy rule (or sell rule) yields are equal to the buy and hold strategy yields. 
Step 2: logically deal with the closing price data, $\mathrm{R}_{\mathrm{t}}=\ln$ $\left(\mathrm{P}_{\mathrm{t}}\right)-\ln \left(\mathrm{P}_{\mathrm{t}-1}\right)$, and through the trading rules to filter out the rules obtained by the buying sequence and by the sell sequence.

Step 3: The buy (sell) group yield sequence and the original rate of return of the sequence of the return of the sample, and calculate the sampling income, buy (sell) group average rate of return and the original average rate of return difference, into the empirical distribution of the sample formation.

Step 4: Repeat the third step ten thousand times, get experience distribution.

Step 5: Judge by experience, reject the original hypothesis or accept the original hypothesis.

\section{B. The Choice of Data}

In this paper, the CSI 300 index is more suitable for research data. CSI 300 index covering the stock market in Shanghai and Shenzhen, the sample stocks' stability is high, free liquidity is relatively large, more suitable for this empirical study.

TABLE I. CSI 300 INDEX Yield DATA STATISTICS

\begin{tabular}{|c|c|c|c|}
\hline Time interval & $\begin{array}{c}2005.1 .4- \\
2016.8 .19\end{array}$ & $\begin{array}{c}\text { Standard } \\
\text { deviation }\end{array}$ & 0.0187 \\
\hline samples & 2826 & Kurtosis & 6.1956 \\
\hline Mean & 0.0004 & Skewness & -0.5045 \\
\hline
\end{tabular}

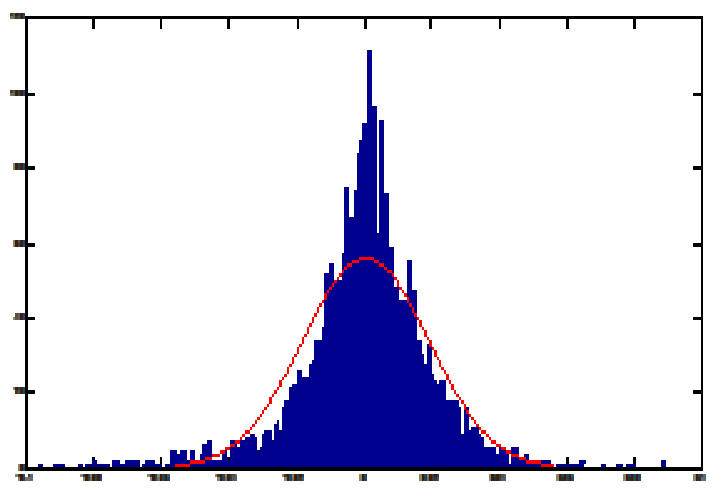

Figure 1. CSI 300 index yield rate distribution histogram

It can be deduced from Table I and Figure 1 that the yield of the CSI 300 Index does not conform to the normal distribution and there is a non-normal feature such as the peak and the tail of the stock. Therefore, if the traditional $t$ test is used, the test results are not reliable, so this paper uses the bootstrap method instead of the traditional $t$ test.

\section{Transaction Costs}

Transaction costs directly affect the benefits of trading strategies, cannot be ignored. In reality, technical indicators are often used for short-term investment operations, and each transaction is required to pay the stock transaction fee, which is likely to erode the benefits of trading strategies. When a transaction strategy is very frequent, transaction costs will become a heavy burden, may lead to the excess of the transaction strategy is negative, so consider the effectiveness of trading strategies, the transaction costs must take into account.

The stock transaction rate is about $0.43 \%$, which has a huge impact on the yield of the trading strategy, and the relatively frequent trading strategy faces a greater rate burden. Fund as a large institutional, when buying and selling stocks to the broker to pay the commission is even lower, the integrated cost of about $0.28 \%$. As the CSI 300 index investors are generally large institutions, so the following are the institutional transaction costs $0.28 \%$ as a comparison or adjustment of the number.

When dealing with transaction strategy transaction costs, if each transaction time to consider the cost of the transaction, will be very cumbersome and complex. This article will refer to the "Break-Even Cost" approach proposed by Bessembinder and Chan [13]. "Break-Even Cost" method is not to calculate the transaction cost itself, but to calculate the transaction to break even when the break-even point, the transaction cost is how much to determine whether the transaction strategy after considering the transaction costs are valid. The core idea of this approach is to calculate the average excess earnings per transaction, which is the balance of transaction costs. With the formula that is:

$\mathrm{C}=\frac{\sum_{1}^{\mathrm{N}} \mathrm{R}}{\mathrm{n}}$

Where $\mathrm{C}$ represents the balance of transaction costs; $\mathrm{R}$ represents the excess rate of the trading strategy; $\mathrm{N}$ represents the number of days of the strategy; $n$ represents the total number of transactions. From the calculation formula we can see that $\mathrm{C}$ itself is the average excess return on each transaction of the trading strategy and represents the maximum transaction cost that the transaction strategy can receive on average for each transaction. The equilibrium transaction cost approach also illustrates the effect of the "double or out" strategy on profitability of trading rules. "Double or out" strategy is when the buy signal, investors borrowed funds to double investment, through the leverage to expand the income; and the emergence of the signal, the investor will be the principal loan, access to risk-free income. Under this assumption, as long as the balance of transaction costs is greater than the actual transaction costs, through the lever can make the excess returns can be amplified, making the excess returns significantly; and when the balance of transaction costs is less than the actual transaction costs, the trading strategy in considering transaction costs, Will not get positive gains.

\section{Asynchronous Transaction}

Asynchronous trading refers to the investors cannot receive the signal from the time, immediately trading. In the real investment operation, investors often cannot grasp the transaction signal to operate. First of all, many technical indicators apply to the closing price as a parameter of the index, which makes the transaction signal appears, the stock market has closed, cannot be traded. Second, even if the investor receives a transaction signal, it may also reflect the 
delay, or cannot respond to the signal in time, resulting in the transaction cannot be carried out immediately. Finally, in some special circumstances, such as daily limit, limit or suspension of the situation, even if investors receive a signal, the reaction is timely, cannot be traded.

In this paper, "buy a lag behind the day, the sale is not lagging behind" approach, that is, when the receipt of the buy signal, investors reflect the delay, or cannot respond to the signal in time, resulting in the transaction cannot be immediately, investors opened the next day For investors to receive a sell signal, out of the "loss of disgust" consideration, the investor opened the next day when the opening transaction, but only the calculation of the day income, The next day earnings are not included in the operation of the proceeds of concentration.

\section{EMPIRICAL RESULTS}

VMA (S, 1, b), FMA (s, 1, h, b), KDJ, MACD; where s represents the short term $(\mathrm{s}=1,5,20), 1$ represents the $\operatorname{long}(\mathrm{L}=5,20,60), \mathrm{b}$ represents the set threshold, and if $\mathrm{b}$ is equal to 0 , there are only two states of buy and sell, and if $b$ is not equal to 0 , there are three states, buy, sell and no operation.

\section{A. The Impact of Asynchronous Transactions}

TABLE II. VMA $(1,5,0)$ EMPIRICAL ANALYSIS STATISTICS

\begin{tabular}{|c|c|c|c|c|c|}
\hline & \multirow{2}{*}{$\begin{array}{c}\text { Buy } \\
\text { and } \\
\text { holding }\end{array}$} & \multicolumn{2}{|c|}{$\begin{array}{c}\text { No consider asynchronous } \\
\text { transactions VMA(1,5,0) }\end{array}$} & \multicolumn{2}{c|}{$\begin{array}{c}\text { consider asynchronous } \\
\text { transactions VMA(1,5,0) }\end{array}$} \\
\cline { 3 - 6 } & buy & sell & buy & sell \\
\hline $\begin{array}{c}\text { Accumulated } \\
\text { income }\end{array}$ & 1.2308 & 14.3892 & 13.1596 & 7.7992 & 6.5796 \\
\hline Mean & 0.0004 & 0.0094 & 0.0102 & 0.0065 & 0.0040 \\
\hline Std & 0.0187 & 0.0139 & 0.0181 & 0.0125 & 0.0211 \\
\hline $\begin{array}{c}\text { Number of } \\
\text { transactions }\end{array}$ & - & 336 & 336 & 258 & 258 \\
\hline Break-Even Cost & - & 0.0392 & 0.0355 & 0.0255 & 0.0207 \\
\hline Sharp ratio & - & 0.6556 & 0.5442 & 0.4997 & 0.1766 \\
\hline Significance & - & $* * *$ & $* * *$ & $* * * *$ & $* * *$ \\
\hline
\end{tabular}

From Table II, we can see that the cumulative yield of VMA $(1,5,0)$ before and after considering the asynchronous transaction is huge, and the cumulative yield of the buy and sell without considering the asynchronous transaction is about 12 times of buying and holding 11 times, consider the cumulative yield of asynchronous buy and sell is about to buy and hold 6 times and 5.5 times, consider the asynchronous transaction, buy rules and sell the rules of the total income fell sharply more than $50 \%$, We can see that asynchronous trading problems on technology analysis trading strategy is very large, ignoring asynchronous transactions may exaggerate the benefits.

Table II also shows that the excess returns are still significantly greater than zero, regardless of the buy rule or the sell rule.

\section{B. VMA $(s, l, 0)$ and VMA $(s, l, 0.01)$}

After analysis Table III, it can be found that in the six buying (selling) rules trading strategies of VMA $(\mathrm{s}, 1,0)$, only the VMA $(1,5,0)$, VMA $(1,20,0)$ and $\operatorname{VMA}(1,60,0)$ can achieve significant excess returns, and other trading strategies are not necessarily valid. But it can be seen that with the increase of the length of the moving average, the cumulative earnings, average daily gains and the number of transactions are declining. It can be seen that the moving average trading strategy is more effective in the short term, and the effective degree is weakened with the increase of the average calculation cycle length.

\section{TABLE III. VMA(S,L,0) EMPIRICAL ANALYSIS STATISTICS}

\begin{tabular}{|c|c|c|c|c|c|c|c|c|}
\hline VMA(s,,,0) & $\begin{array}{c}\text { Accum } \\
\text { ulated } \\
\text { income }\end{array}$ & Mean & Std & $\begin{array}{c}\text { Numb } \\
\text { er of } \\
\text { transa } \\
\text { ctions }\end{array}$ & $\begin{array}{c}\text { Break- } \\
\text { Even } \\
\text { Cost }\end{array}$ & $\begin{array}{c}\text { Sharp } \\
\text { ratio }\end{array}$ & $\begin{array}{c}\text { Signifi } \\
\text { cance }\end{array}$ \\
\hline \multirow{2}{*}{$\begin{array}{c}\text { Buy and } \\
\text { holding }\end{array}$} & 1.2308 & 0.0004 & 0.0187 & & & & \\
\hline \multirow{2}{*}{$\mathbf{1 - 5}$} & buy & 7.7992 & 0.0065 & 0.0125 & 258 & 0.0255 & 0.4997 & $* * *$ \\
\cline { 2 - 9 } & sell & 6.5796 & 0.0040 & 0.0211 & 258 & 0.0207 & 0.1766 & $* * *$ \\
\hline \multirow{2}{*}{$\mathbf{1 - 2 0}$} & buy & 5.4104 & 0.0038 & 0.0146 & 101 & 0.0414 & 0.2416 & $* * *$ \\
\cline { 2 - 9 } & sell & 4.1508 & 0.0030 & 0.0217 & 101 & 0.0289 & 0.1243 & $* * *$ \\
\hline \multirow{2}{*}{$\mathbf{1 - 6 0}$} & buy & 3.6831 & 0.0026 & 0.0162 & 55 & 0.0446 & 0.1424 & $* * *$ \\
\cline { 2 - 9 } & sell & 2.4430 & 0.0018 & 0.0209 & 55 & 0.0220 & 0.0711 & $* *$ \\
\hline \multirow{2}{*}{$\mathbf{5 - 2 0}$} & buy & 2.5214 & 0.0017 & 0.0169 & 76 & 0.0170 & 0.0837 & $* *$ \\
\cline { 2 - 9 } & sell & 1.2618 & 0.0010 & 0.0205 & 76 & 0.0004 & 0.0319 & \\
\hline \multirow{2}{5}{$\mathbf{5 - 6 0}$} & buy & 2.6039 & 0.0018 & 0.0171 & 34 & 0.0404 & 0.0884 & $* *$ \\
\cline { 2 - 9 } & sell & 1.3638 & 0.0010 & 0.0204 & 34 & 0.0039 & 0.0349 & \\
\hline \multirow{2}{20-60}{} & buy & 1.9652 & 0.0014 & 0.0182 & 23 & 0.0319 & 0.0594 & \\
\cline { 2 - 8 } & sell & 0.7251 & 0.0005 & 0.0193 & 23 & -0.0220 & 0.0116 & \\
\hline
\end{tabular}

TABLE IV. VMA(S,L,0) EMPIRICAL ANALYSIS STATISTICS

\begin{tabular}{|c|c|c|c|c|c|c|c|c|}
\hline \multicolumn{2}{|c|}{ VMA(s,l,0.01) } & $\begin{array}{c}\text { Accumul } \\
\text { ated } \\
\text { income }\end{array}$ & Mean & Std & $\begin{array}{c}\text { Number } \\
\text { of } \\
\text { transacti } \\
\text { ons }\end{array}$ & $\begin{array}{c}\text { Break- } \\
\text { Even } \\
\text { Cost }\end{array}$ & $\begin{array}{c}\text { Sharp } \\
\text { ratio }\end{array}$ & $\begin{array}{c}\text { Signifi } \\
\text { cance }\end{array}$ \\
\hline \multicolumn{2}{|c|}{$\begin{array}{l}\text { Buy and } \\
\text { holding }\end{array}$} & 1.2308 & 0.0004 & 0.0187 & & & & \\
\hline \multirow[t]{3}{*}{$1-5$} & buy & 5.4013 & 0.0091 & 0.0127 & 200 & 0.0209 & 0.6918 & **** \\
\hline & sell & 11.7984 & 0.0163 & 0.0201 & 278 & 0.0380 & 0.7928 & **** \\
\hline & non & 0.0601 & & & & & & \\
\hline \multirow[t]{3}{*}{$1-20$} & buy & 4.9734 & 0.0042 & 0.0149 & 102 & 0.0367 & 0.2631 & **** \\
\hline & sell & 6.5663 & 0.0064 & 0.0214 & 120 & 0.0445 & 0.2840 & $* * *$ \\
\hline & non & 0.0239 & & & & & & \\
\hline \multirow[t]{3}{*}{$1-60$} & buy & 3.6084 & 0.0028 & 0.0165 & 45 & 0.0528 & 0.1510 & $* * *$ \\
\hline & sell & 3.5423 & 0.0030 & 0.0214 & 65 & 0.0356 & 0.1277 & $* * *$ \\
\hline & non & 0.0124 & & & & & & \\
\hline \multirow[t]{3}{*}{$5-20$} & buy & 2.2164 & 0.0019 & 0.0175 & 73 & 0.0135 & 0.0917 & *** \\
\hline & sell & 1.5332 & 0.0016 & 0.0219 & 72 & 0.0042 & 0.0580 & \\
\hline & non & 0.0266 & & & & & & \\
\hline \multirow[t]{3}{*}{$5-60$} & buy & 2.7790 & 0.0021 & 0.0173 & 27 & 0.0573 & 0.1068 & **** \\
\hline & sell & 1.5316 & 0.0013 & 0.0212 & 37 & 0.0081 & 0.0489 & \\
\hline & non & 0.0131 & & & & & & \\
\hline \multirow{3}{*}{$\begin{array}{l}20- \\
60\end{array}$} & buy & 1.9742 & 0.0015 & 0.0187 & 21 & 0.0354 & 0.0667 & $*$ \\
\hline & sell & 0.7438 & 0.0007 & 0.0202 & 23 & 0.0212 & 0.0183 & \\
\hline & non & 0.0152 & & & & & & \\
\hline
\end{tabular}

Contrast Table III and Table IV, it can be seen that the level of significance of VMA (s, 1, 0.01) relative to VMA (s, $1,0)$ is not significantly changed, and the significance level is similar. The trading strategy is more effective in the short term, and the degree of effectiveness is gradually weakened with the increase in the length of the average calculation cycle. However, it can be found that the cumulative gain(VMA $(1,5,0.01)$, VMA $(1,20,0.01)$ and VMA $(1,60,0.01))$ of the sell rule has a large change in the cumulative gain(VMA $(1,5,0)$, VMA $(1,20,0)$ and VMA $(1,60,0))$ relative to the sell rule, but the buying rule has not changed much. The results also show that buying rules trading strategies of VMA $(5,20,0.01)$ and VMA $(20,60,0.01)$ excess returns significantly larger than zero, but selling rules trading strategies of VMA $(5,20,0.01)$ and VMA $(20,60,0.01)$ excess returns are not significant.

\section{FMA $(s, l, h, 0.01)$}

From table V, we find that only FMA $(1,5,5,0.01)$ and FMA $(1,20,5,0.01)$ buy (sell) rules can achieve significant excess returns, other trading strategies are not necessarily 
fully effective. At the same time we find that the moving average trading strategy is more effective in the short term, and the effective degree is weakened with the increase of the average calculation cycle length.

At the same time we tested the different $\mathrm{h}$ (holding period) strategy , for example, FMA $(1,20, \mathrm{~h}, 0.01)$, it can be find that FMA $(1,20,7,0.01)$ buy(sell)rules excess returns are still significantly greater than zero, but FMA $(1,20,8,0.01)$ buy rule excess returns are greater than zero, but the excess returns of the selling rules are not significant. $(\mathrm{S}, 1, \mathrm{~h}, 0.01)$ strategy, the different holding period of the excess returns also have an impact, further found that the shorter holding period, the higher the significance.

TABLE V. FMA(S,L,0.01) EMPIRICAL ANALYSIS STATISTICS

\begin{tabular}{|c|c|c|c|c|c|c|c|c|}
\hline \multicolumn{2}{|c|}{$\underset{f}{\text { FMA(s,l,h,0.01 }}$} & \multirow{2}{*}{$\begin{array}{c}\begin{array}{c}\text { Accumul } \\
\text { ated } \\
\text { income }\end{array} \\
3.0842 \\
\end{array}$} & \multirow{2}{*}{\begin{tabular}{|l} 
Mean \\
0.0031
\end{tabular}} & \multirow{2}{*}{\begin{tabular}{|c|} 
Std \\
0.0170
\end{tabular}} & \multirow{2}{*}{$\begin{array}{c}\begin{array}{c}\text { Number of } \\
\text { transaction } \\
\text { s }\end{array} \\
147 \\
\end{array}$} & \multirow{2}{*}{$\begin{array}{c}\begin{array}{c}\text { Break- } \\
\text { Even } \\
\text { Cost }\end{array} \\
0.0126 \\
\end{array}$} & \multirow{2}{*}{$\begin{array}{l}\begin{array}{c}\text { Sharp } \\
\text { ratio }\end{array} \\
0.1657\end{array}$} & \multirow{2}{*}{$\begin{array}{c}\text { Signifi } \\
\text { cance }\end{array}$} \\
\hline $1-5-5$ & buy & & & & & & & \\
\hline & sell & 4.6481 & 0.0041 & 0.0214 & 173 & 0.0198 & 0.1757 & $* * *$ \\
\hline & non & 0.0275 & & & & & & \\
\hline \multirow[t]{3}{*}{$1-20-5$} & buy & 2.7440 & 0.0021 & 0.0168 & 80 & 0.0189 & 0.1052 & $* * *$ \\
\hline & sell & 2.5309 & 0.0021 & 0.0211 & 85 & 0.0153 & 0.0851 & $* *$ \\
\hline & non & 0.0111 & & & & & & \\
\hline \multirow[t]{3}{*}{$1-20-7$} & buy & 2.4370 & 0.0018 & 0.0174 & 70 & 0.0172 & 0.0846 & *** \\
\hline & sell & 2.0689 & 0.0017 & 0.0207 & 64 & 0.0131 & 0.0667 & $*$ \\
\hline & non & 0.0079 & & & & & & \\
\hline \multirow[t]{3}{*}{$1-20-8$} & buy & 2.5787 & 0.0019 & 0.0172 & 63 & 0.0214 & 0.0925 & *** \\
\hline & sell & 1.7946 & 0.0014 & 0.0208 & 65 & 0.0087 & 0.0537 & \\
\hline & non & 0.0071 & & & & & & \\
\hline \multirow[t]{3}{*}{$1-60-5$} & buy & 2.8670 & 0.0021 & 0.0169 & 36 & 0.0455 & 0.1089 & *** \\
\hline & sell & 1.9734 & 0.0016 & 0.0210 & 43 & 0.0173 & 0.0597 & \\
\hline & non & 0.0064 & & & & & & \\
\hline \multirow[t]{3}{*}{$5-20-5$} & buy & 1.9651 & 0.0015 & 0.0179 & 68 & 0.0108 & 0.0694 & * \\
\hline & sell & 0.9573 & 0.0009 & 0.0211 & 68 & -0.0040 & 0.0265 & \\
\hline & non & 0.0168 & & & & & & \\
\hline \multirow[t]{3}{*}{$5-60-5$} & buy & 2.3477 & 0.0017 & 0.0177 & 27 & 0.0414 & 0.0820 & $* *$ \\
\hline & sell & 1.2769 & 0.0011 & 0.0206 & 34 & 0.0014 & 0.0367 & \\
\hline & non & 0.0086 & & & & & & \\
\hline \multirow[t]{3}{*}{$20-60-5$} & buy & 1.7430 & 0.0013 & 0.0188 & 21 & 0.0244 & 0.0546 & \\
\hline & sell & 0.4335 & 0.0004 & 0.0199 & 23 & -0.0347 & 0.0038 & \\
\hline & non & 0.0119 & & & & & & \\
\hline
\end{tabular}

\section{KDJ and $M A C D$}

TABLE VI. KDJ AND MACD EMPIRICAL ANALYSIS STATISTICS

\begin{tabular}{|c|c|c|c|c|}
\hline \multirow{2}{*}{} & \multicolumn{2}{|c|}{ KDJ } & \multicolumn{2}{c|}{ MACD } \\
\cline { 2 - 5 } & buy & sell & buy & sell \\
\hline $\begin{array}{c}\text { Accumulated } \\
\text { income }\end{array}$ & 4.9281 & 8.2284 & 2.3933 & 1.2032 \\
\hline Mean & 0.0040 & 0.0062 & 0.0016 & 0.0009 \\
\hline Std & 0.0149 & 0.0197 & 0.0171 & 0.0204 \\
\hline $\begin{array}{c}\text { Number of } \\
\text { transactions }\end{array}$ & 221 & 261 & 39 & 39 \\
\hline $\begin{array}{c}\text { Break-Even } \\
\text { Cost }\end{array}$ & 0.0167 & 0.0268 & 0.0380 & 0.0075 \\
\hline Sharp ratio & 0.2493 & 0.2988 & 0.0769 & 0.0301 \\
\hline Significance & $* * *$ & $* * *$ & $* *$ & \\
\hline \multicolumn{2}{|l|}{} \\
\hline
\end{tabular}

From Table VI it can be found that the KDJ-based buy (sell) rule can achieve significant excess returns; however, we found that MACD-based buy rules achieves significant excess returns at a 5\% significance level, and the sell rule is not available significant excess returns.

\section{CONCLUSION}

In this paper, the empirical study use the date from January 4, 2005 to August 19, 2016, CSI 300 index, Moving average trading strategy, KDJ and MACD to study the weak effective of China's stock market.

The empirical results show that: If we do not consider the issue of asynchronous trading, it is not in line with the actual situation of investment transactions, which will be exaggerate the benefits, and affect the significance of excess returns. In order to solve the "whipping effect", we use three forms of transaction form. For the same trading strategy, the three forms of transaction form better than the two state of the transaction form, not only can reduce the transaction risk, but also can improve the cumulated income of sale rules. Through the empirical study, we can find that the short-term moving average trading strategy can obtain significant excess returns, but the excess returns of the long-term moving average trading strategy are not significant, so the technical analysis forecasting ability varies with age. KDJ's buy and sell rules can achieve significant excess returns. MACD's buying rules can achieve significant excess returns at a significant $5 \%$ level, and the sell rules cannot achieve significant excess returns.

To sum up, it can be argued that the technical analysis in China's stock market still can achieve excess returns, the Chinese stock market has not yet reached a weak efficient market.

\section{ACKNOWLEDGMENT}

First of all, I would like to extend my sincere gratitude to my supervisor, Guangping Hui, for his instructive advice and useful suggestions on my thesis. Secondly, special thanks should go to my friends who have put considerable time and effort into offering their comments on the draft. Finally, I am indebted to my parents for their continuous support and encouragement.

\section{REFERENCES}

[1] Eugene F. Fama, Marshall E. Blume, Filter Rules and Stock Market Trading Profit, journal of Business.39 (1966)226-241.

[2] Eugene F. Fama, Efficient capital markets: a review of theory and empirical work, Journal of Finance. 25 (1970) 383-423.

[3] Christopher Neely, Paul Weller, Rob Dittmar, Is Technical Analysis in the Foreign Exchange Market Profitable? A Genetic Programming Approach, Journal of Financial and Quantitative Analysis 32 (1997).

[4] Colin Fyfe, John Paul Marney, Heather Tarbert, Risk Adjusted Returns from Technical Trading: A Genetic Programming Approach, Applied Financial Economics. (2005).

[5] Efron B, Bootstrap Methods: Another Look at the Jackknife, The Annals of Statistics. 7 (1979) 1-26.

[6] Brock, William, Josef Lakonishok, and Blake LeBaron, Simple Technical Trading Rules and the Stochastic Properties of Stock Returns, Journal of Finance. 47 (1992) 1731-1764.

[7] Hendrik Bessembinder, Kalok Chan, The Profitability of Technical Trading Rules in the Asian Stock Markets, Pacific-Basin Finance Journal. 3 (1995).

[8] Dai Jie, Wu Kang ping, An Empirical Study on the prediction ability of Technical Analysis in Chinese Stock Market, The Journal of Quantitative \& Technical Economics. 04 (2002)99-102.

[9] Sun Bi bo, Fang Jian wen, A Test on Weak form Efficiency of China's Stock Market: An Empirical Study Based on the Profitability of Technical Trading Rules, Journal of Shanghai University of Finance and Economics. 06 (2004) 52-57. 
[10] Sun Bi bo, Is the moving average useful? - An empirical study based on the Shanghai Composite Index, The Journal of Quantitative \& Technical Economics. 02 (2005) 149-156.

[11] Ryan Sullivan, Allen Timmermann, Halbert White, Data Snooping, Technical Trading Rule Performance, and the Bootstrap, Journal of Finance. 10 (1999).
[12] LI Sha, LI Hong gang, Validity of Technical analysis in the Stock Market: A Practical case, Journal of Beijing Normal University (Natura 1 Science). 04 (2009) 212-214.

[13] Bessembinder H., Chan K, Market efficiency and the returns to technical analysis, Financial Management. 27 (1998)5-17. 